\title{
Editorial
}

\section{Nonthermal Plasma for Food Quality and Safety}

\author{
Vladimír Scholtz $\left(\mathbb{D},{ }^{1}\right.$ Josef Khun, ${ }^{1}$ and Božena Šerá \\ ${ }^{1}$ University of Chemistry and Technology, Prague, Czech Republic \\ ${ }^{2}$ Comenius University, Bratislava, Slovakia \\ Correspondence should be addressed to Vladimír Scholtz; vladimir.scholtz@vscht.cz
}

Received 19 May 2019; Accepted 19 May 2019; Published 1 July 2019

Copyright (C) 2019 Vladimír Scholtz et al. This is an open access article distributed under the Creative Commons Attribution License, which permits unrestricted use, distribution, and reproduction in any medium, provided the original work is properly cited.

Although the microbicidal effects of nonthermal plasma (NTP-the cold ionised gas) were reported more than fifteen years ago, we are still waiting for its wider application in practice. Though there are lots of published scientific papers describing the reduction and inactivation of pathogenic microorganisms (e.g., bacteria and spores) by NTP exercisable in microbiology, in medicine for disinfection of thermolabil instruments and therapy of infections, and in food processing for microbial decontamination of food or production components, their application in practice is still not generally accepted. Nevertheless, it seems the final step of apparatus upscaling and application in practice should become directly.

NTP technology is useable above all in the food industry. NTP can inactivate decontaminated surfaces of various food products and semifinished food products, yet the effect is relatively gentle on surfaces being decontaminated. NTP provides sufficient efficiency accompanied by minimal damage and minimal impact on the quality of processed foods or thermosensitive packaging materials. Thus far, it appears that, at least in some cases, there is minimal damage of antioxidants in food, and the content of substance residues is minimized after the plasma treatment. It is a usable effect that NTP may start better germination and early growth in many agricultural crop seeds.

By our experience from the food and agriculture industry, one of the main reasons may be the skepticism of producers about the effectivity and suitability of NTP and also their unfamiliarity. Nowadays, when the knowledge of NTP effects is general in the scientific area, our next big deal is to present and propagate the potential of NTP to the public community. This special issue proposes to collect a set of several interesting works to catch the attention of potential applicants. This issue includes five original papers and one review.

The first three papers confirm the potential of NTP to decrease the number of food microflora together with the analysis of the quality of treated food. The various food samples they used are both perishable ones such as chicken meat and onion and durable ones such as rice.

The next article together also with the previous ones pays attention to the food quality affection by NTP. The paper presents the study about their influence on both physical and chemical properties such as color, content of antioxidants, fatty acids, protein, sugar, thermodynamic properties, solubility, and $\mathrm{pH}$.

The last but one article addresses the not yet well-known fact of food functionality affection by NTP presented on cereal flour and dough properties.

As a final article, we offer our review summarizing the results of several studies of NTP treatment of wheat grains as one of the world's most important nutritive. We focus mainly on the possible effects of NTP on wheat rather than on the detailed description of plasma generation and other treatments. Details and description of the plasma effect begin at the surface of wheat grains and continue stepwise through the growth characteristics, metabolisms, and matured plants to the flour as the final food product.

We hope that this special issue contributes to familiarize the awareness of NTP features suitable for food industry and that the gentle reader finds it interesting. We wish you a pleasant reading.

\section{Conflicts of Interest}

The editors declare that they have no conflicts of interest.

Vladimír Scholtz Josef Khun Božena Šerá 


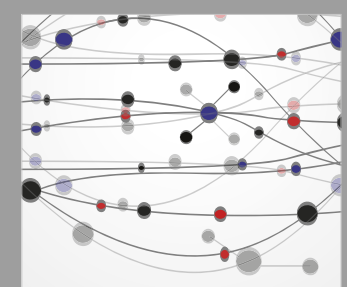

The Scientific World Journal
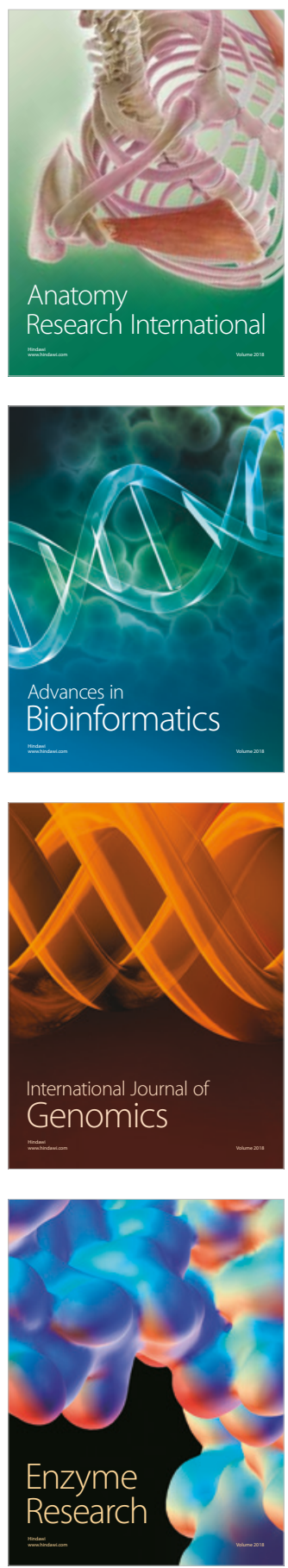
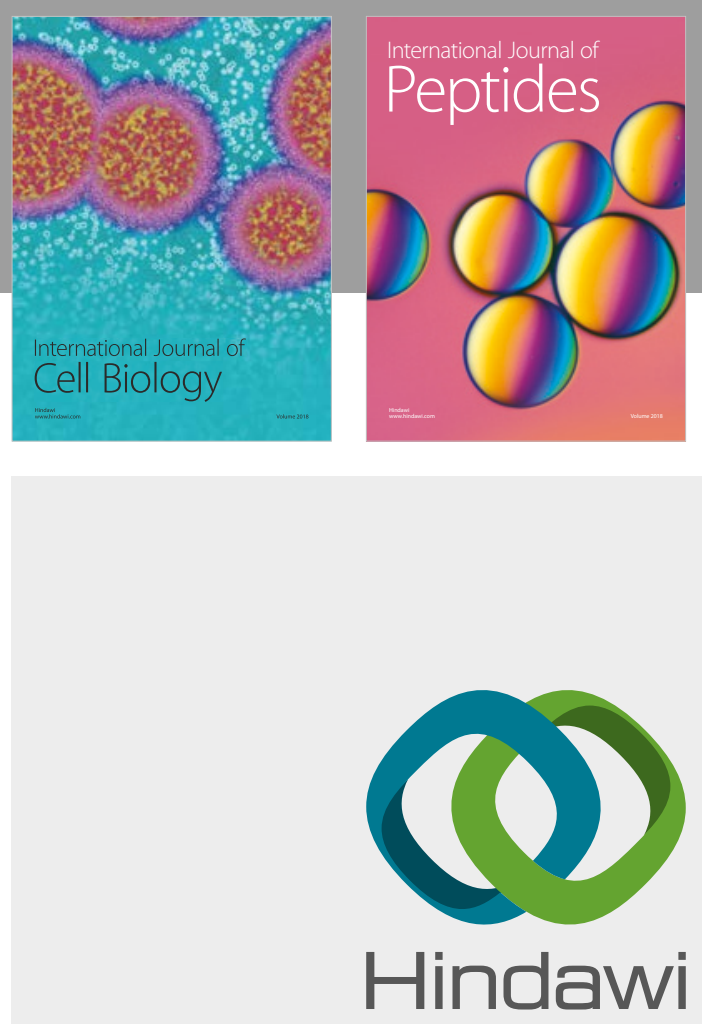

Submit your manuscripts at

www.hindawi.com
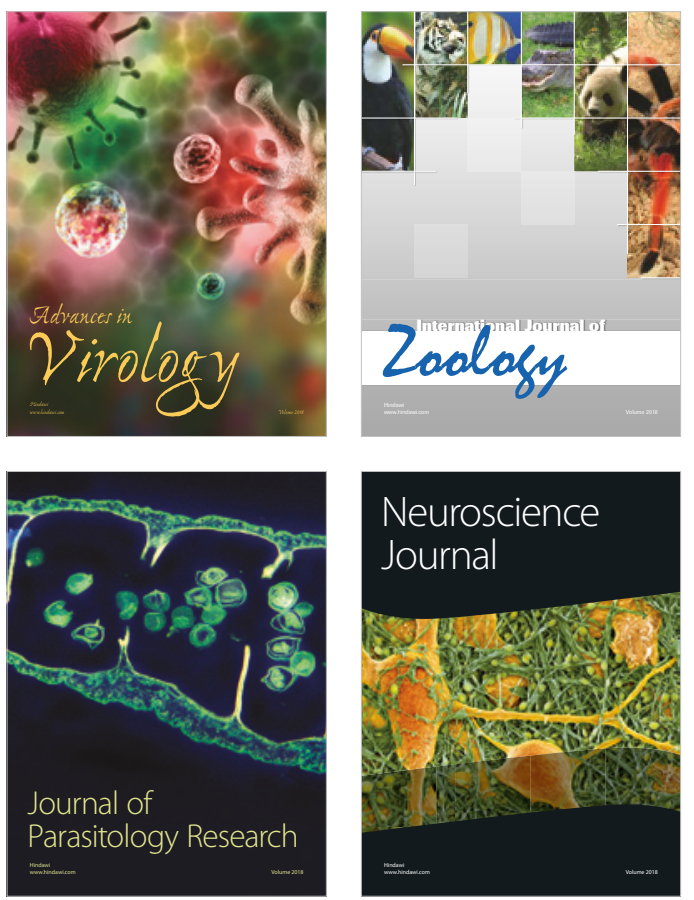
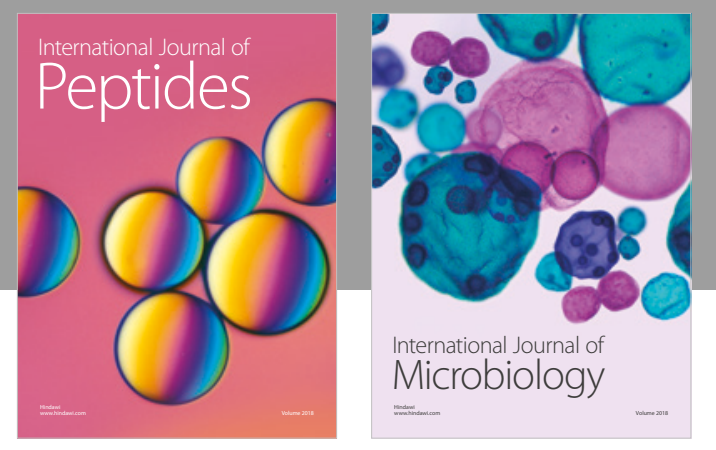

nternational Journal of Microbiology
Journal of
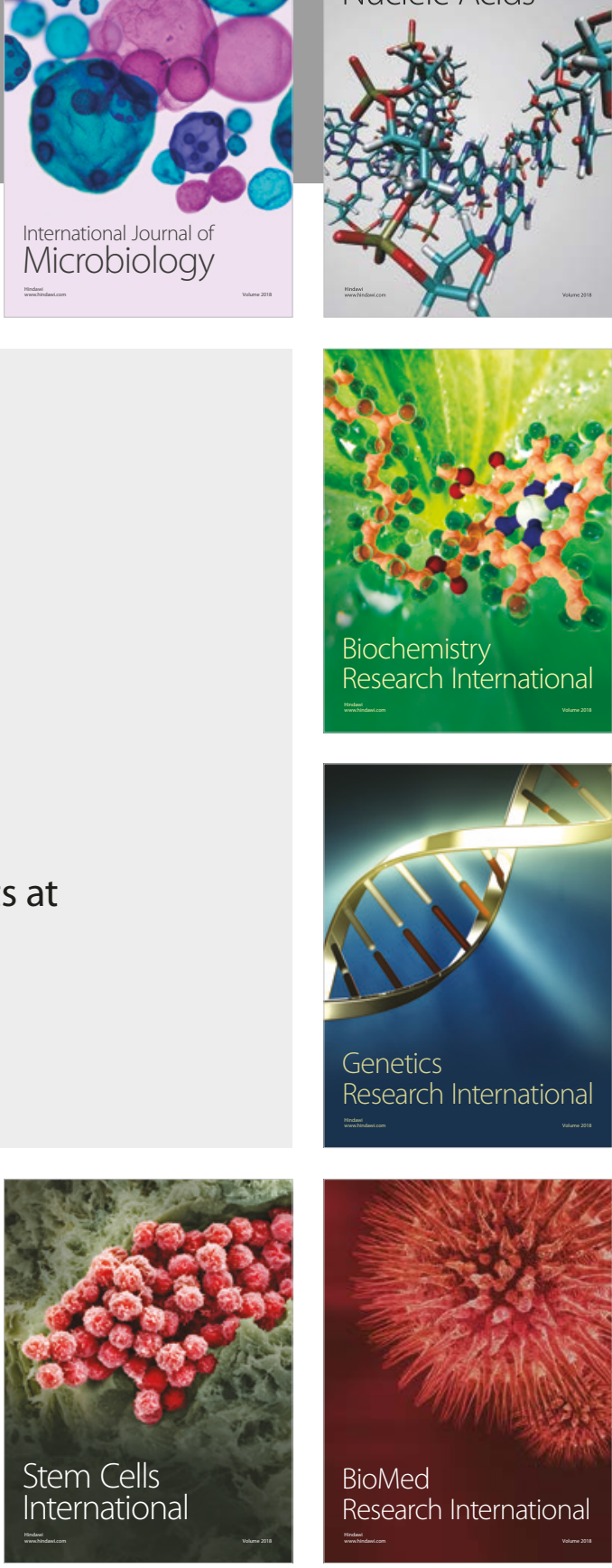
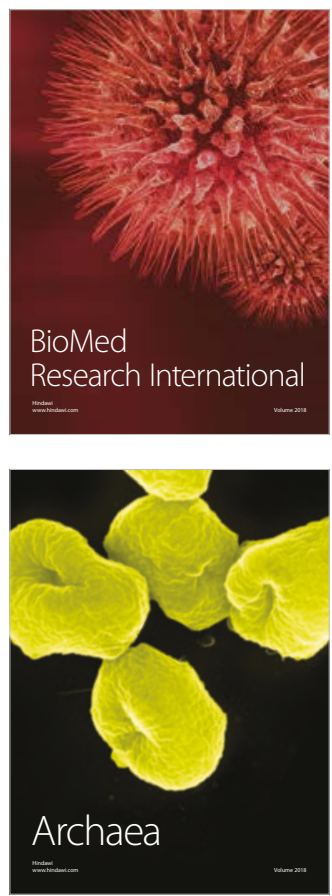